\title{
DESIGN OF THE \\ ADVANCED DIVERTOR PUMP CRYOGENIC SYSTEM FOR DIII-D
}

\author{
by \\ K.M. SCHAUBEL, C.B. BAXI, G.L. CAMPBELL, \\ A.M. GOOTGELD, A.R. LANGHORN, G.J. LAUGHON, \\ J.P. SMITH, P.M. ANDERSON, M.M. MENON*
}

*Oak Ridge National Laboratory

This is a preprint of a paper to be presented at the 14th Symposium on Fusion Engineering, September 30-October 3, 1991, San Diego, California, and to be printed in the Proceedings.

\author{
Work supported by \\ Department of Energy \\ Contract DE-AC03-89ER51114
}
GENERAL ATOMICS PROJECT 3466
NOVEMBER 1991

\section{GENERAL ATOMICS




\title{
DESIGN OF THE ADVANCED DIVERTOR PUMP CRYOGENIC SYSTEM FOR DIII-D
}

\author{
K.M. Schaubel, C.B. Baxi, G.L. Campbell, A.M. Gootgeld, \\ A.R. Langhom, G.J. Laughon, J.P. Smith, P.M. Anderson \\ Generd Atomics \\ P.O. Bou 85608 \\ San Diego, California 92186-9784
}

\author{
M.M. Menon \\ Oak Ridge National Laboratory \\ P.O. Bon 2009 \\ Oak Ridge, Tennewere 37831
}

Abstract: The design of the cryogenic system for the DIII-D advanced divertor cryocondensation pump is presented. The advanced divertor incorporates a baffe chamber and bias ring located near the bottom of the DIII-D vacuum vessed. A 50,000 l/s cryocondensation pump will be installed underneath the baffle for plasma particle exhaust. The pump consirts of a liquid helium cooled tube operating at $4.3^{\circ} \mathrm{K}$ and a liquid nitrogen cooled radiation shieid. Liquid helium is fed by forced flow through the cryopump. Compressed belium gas flowing through the high pressure side of a beat exchanger is regeneratively cooled by the two-phase helium leaving the pump. The cooled high pressure gaseous helium is then liquefied by a Joule-Thomson expansion valve. The liquid is returned to a storage dewar. The liquid nitrogen for the radiation shield is supplied by forced flow from a bulk storage system. Control of the cryogenic system is accomplished by a programmable logic controller.

\section{Introduction}

The Advanced Divertor (AD) has been operational in the DIII-D tolamak since September of 1990 . It is currently being utilized to study biasing of divertor plasma configurations and baffling at the divertor separatrix-wall interface to allow pressure buildup in anticipation of future pumping experiments. Ade quate pressure buildup was observed to allow meaningful pumping to take place [1]. Thus, the advanced divertor cryopump is currently being constructed for installation in early 1992 and will be used to control plaserse density by particie exhaust [2].

The AD configuration consists of a circular shaped inconel electrode which is biasable and a baffle chamber located inside of the DIII-D vacuum chamber as shown in Fig. 1. The cryopump will be located in the space beneath the gas baffle. Hydrogen or deuterium will be pumped by cryocondensation onto a metal surface at $4.3^{\circ} \mathrm{K}$. The pumping surface area is approsimately $1 \mathrm{~m}^{2}$ and will be convectively cooled by a forced flow of two-phase helium at a pressure of $116 \mathrm{kPa}$ (2 psig).

Distribution and control of liquid belium and liquid nitrogen will be accomplished by a system which will form an integrated part of the DIII-D cryogenic system. This paper will describe the design of the $A D$ cryogenic system.

\section{Cryopump Configuration}

The AD cryopump will be located beneath the bafle as shown in Fig. 1. Particles being pumped will flow through the space between the bias ring and the floor tiles of the DIII-D vacuum vessel. The geometry of the pump has been optimized using the particle transport code DEGAS 2 ! . The pump is designed for a nominal gas throughput of $2700 \mathrm{~Pa}-1 / \mathrm{s}(20 \mathrm{torr}-1 / \mathrm{s})$ with a calculated effective pumping speed of $50,000 \mathrm{l} / \mathrm{s}$ for deuterium. It will consist of two coaxial tubes which are cooled by counter-flowing liquid helium, a pair of liquid nitrogen cooled thermal radiation shields, and an outer secondary shield. The secondary shieid will be used to reduce thermal radiation to the nitrogen shield from the vacuum vessel wails and baffle plates and to prevent water vapor desorption due to energetic particles striking the liquid nitrogen shield. When viewed in plan, the cryopump will be a non-continuous ring with a short gap to avoid creating an inductive loop which would result in large electromagnetic forces on the cryopump. The helium cooled tube will have a leagth of about $10 \mathrm{~m}$ and a surface area of $1 \mathrm{~m}^{2}$ and is fed at only one point toroidally with the counter-flow arrangement providing the helium return. The cryogen feed points will be located 180 deg from the gap. Reference [3] gives a detailed description of the in-vessel cryopump design.

\section{Existing DIILD Croosetem}

The existing DIII-D cryogenic system supplies liquid belium to the neutral beam injector cryopanels and the superconducting magnets for the $110 \mathrm{GHz}$ and $60 \mathrm{GHz}$ electron cyclotron heating (ECE) systems $[4,5]$. The helium system is a clowed loop. The boil-off gas is continuously recovered and reliquefied. Liquid nitrogen from bulk storage is used for the neutral beamline $80^{\circ} \mathrm{K}$ cryopanela, thermal radiation shielding of liquid helium cooled components, and in the belium liquefier gas precooler. The liquid nitrogen system is open loop with the exhourt gas being vented to atmosphere. In addition to the AD cryopump, future plans include the addition of a hydrogen pellet injector which will also require liquid helium and liquid nitrogen.

A simplified flow diagram of the existing closed loop belium cryogenic system is shown in Fig. 2. The proposed AD cryopump and peilet injector systems are shown in phantom for reference. A $50 \mathrm{~g} / \mathrm{s}$ (600 SCFM) screw compressor supplies 1.6 $\mathrm{MPa}(220$ psig) helium gas to the liquefier and the neutral beam re-liquefier. The high and low pressure lines are kept at constant pressure by a gas management system consisting of the makeup, dump, and bypass valves and gaseous helium storage tanks. The helium liquefier discharges saturated liquid helium into a $3800 \mathrm{I}$ dewar at $140 \mathrm{kPa}$ (6 psig). The dewar pressure
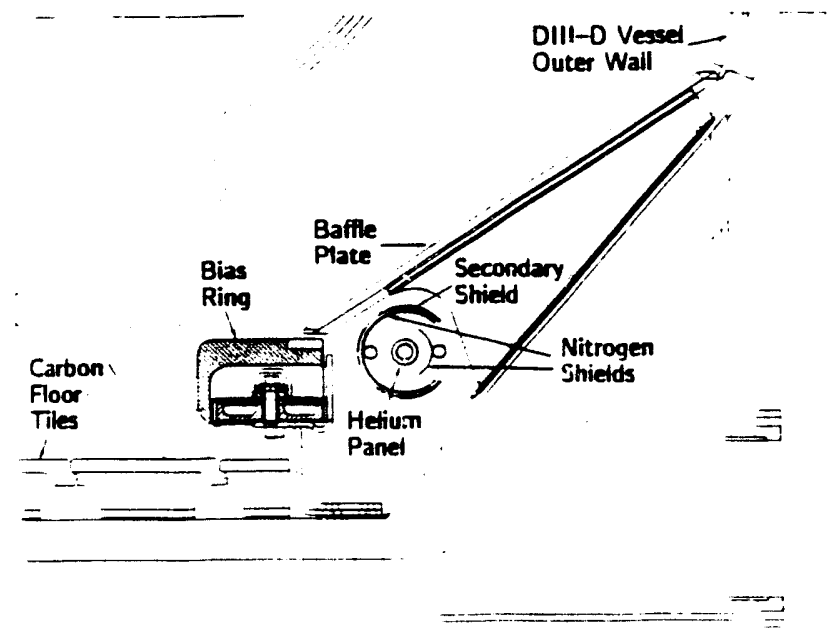

Fig. 1. DIII-D advanced divertor configuration r.ross sectional view. 


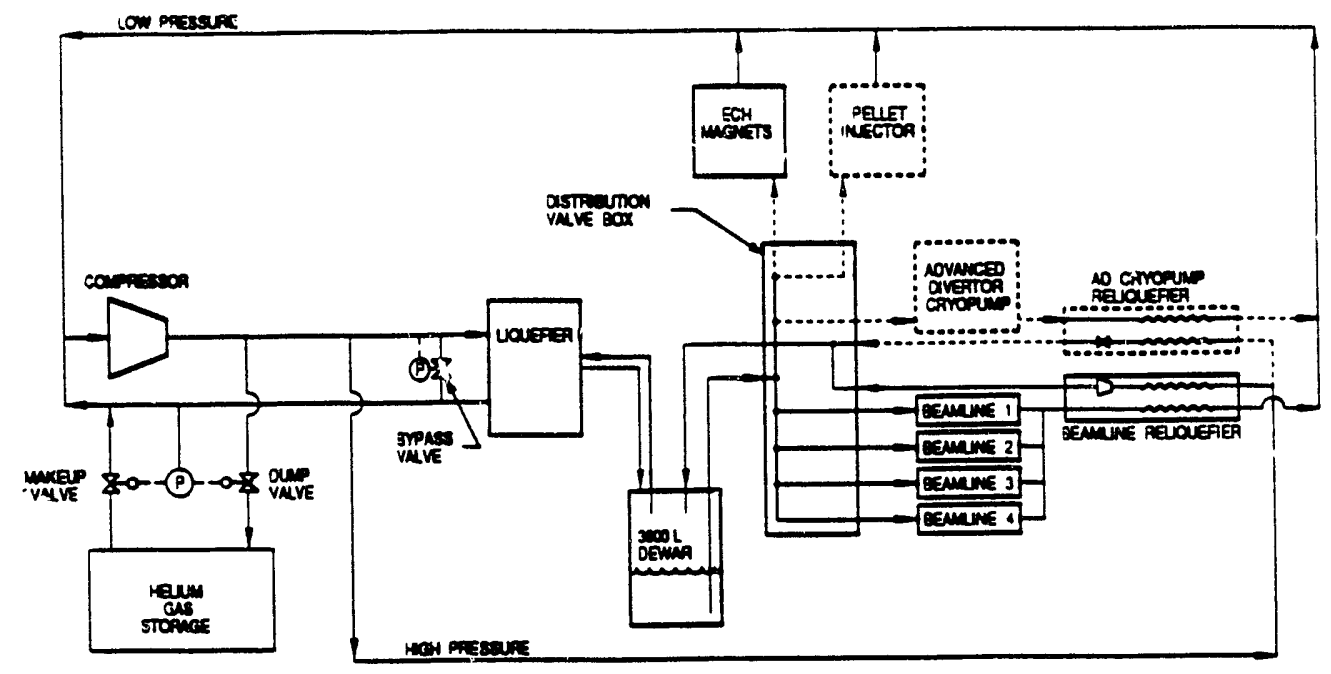

Fic. 2. Simplified DIILD helium eryosystem flow diagram (present sysem shown in solid, planned additions shown in pinantom).

is maintained constant to drive the flow of liquid helium to the beamlines. A distribution valve box is used to independently distribute the flow of liquid helium and nitrogen to the beamlines. The ECH superconducting magnets are batch filled from fortable dewars. 'The cryogenic system operates continuously during DIII-D run periods.

The present DIII-D helium liquefier operates near its full capacity when serving the four neutral beam injectors and the ECH magnets. The addition of the AD cryopump and peilet injector will require a larger liquefier winich is planned for installation in early 1993. Until then, it is planned that one of the four beamilines will be shut down to provide enough liquid belium during $A D$ cryopump operation. Table 1 lists the present and planned DIII-D cryogenic system parameters.

\section{Advanced Divertor Cryogenic System}

The AD cryopump system will form a part of the DIII-D cryogenic system. The existing system will be upgraded to include the required cryogen distribution, control, and recovery hardware for the AD cryopump. A programmable logic controller (PLC) based system will automatically control cooldown. regeneration, steady-state operation and warmup of the $A D$ cryosystem. The cryopump will be convectively cooled by a forced flow of liquid helium through its coaxial tubular geometry. Saturated liquid belium will enter the pump at $116 \mathrm{kPa}$ and at a flow rate of $5 \mathrm{~g} / \mathrm{s}$. A liquid nitrogen cooled shield will surround the helium cryopump. The liquid aitrogen shield will be cooled by a combination of two-phase forced flow convection through a tube and heat conduction through an attached thin walled shell. Liquid nitrogen at $140 \mathrm{kPa}$ will enter the shield at a flow rate of $10 \mathrm{~g} / \mathrm{s}$.

Two cooling optinns were considered in the cryopump design: (1) supercritical helium cooiing, and (2) two-phase forced flow convection. The first option has the advantage that potential flow instabilities associated with two-phase flow are eliminated. However, super-critical helium flow rates would have to be higher for a given amount of heat remosal, and the temperature of supercritical helium is too high for pumping hydrogen at an acceptable vapor pressure without considerable subcooling. Therefore, the second option (two-phase forced flow convection) was chosen.

The configuration of the AD cryogenic system will be very similar to that of the proven neutral beam cryogenic system to minimize the possibility of two-phase flow instability. Experiments using a prototypic cryopump were performed to prove the coaxial counter-flow helium panel design $6 !$. The results show that flow stability through the belium panel is maintained at steady-state cryopanel heat loads as bigh as $54 \mathrm{~W}$. In addition, it was shown that the helium panel alone can be completely cooled from near room temperature in about $5 \mathrm{~min}$ at the design flow rate of $5 \mathrm{~g} / \mathrm{s}$.

A simplified cyogenic flow diagram is shown in Fig. 3. Table 2 summarizes the thermodynamic conditions at various points in the system. Liquid helium will flow from the pressurized dewar to the distribution valve box. It wiil then flow through a subcooler where it will be cooled to $4.4^{\circ} \mathrm{K}$. The subcooled helium will drop lower in temperature as it is throttled into the cryopump through an automatic flow control valve. The helium will enter the cryopanel as nearly $100 \%$ liquid and exhaust as a low quality mixture after absorbing thermal energy. The two-phase stream will then pass through the subcooler and heat exchanger/boiler where it will be fully vaporized and warmed to nearly room temperature before returning to compreseor suction.

High pressure helium gas from the compressor will be regeneratively cooled by the two-phase helium returning from the cryopurop. The high pressure helium will be cooled to $4.8^{\circ} \mathrm{K}$ in the heat exchanger and then partially liquefied by JouleThomson expansion. The two-phase helium will return to tne dewar at $4.6^{\circ} \mathrm{K}$ and $140 \mathrm{kPa}$. The liquid portion will fill the dewar while the cold gas passes through the low pressure side of

Table 1

DIII-D Cryogenic System Parameters

\begin{tabular}{|c|c|c|}
\hline & Present & Planned \\
\hline \multicolumn{3}{|l|}{ Helium System } \\
\hline Liquefaction capacity & $80 \mathrm{l} / \mathrm{h}$ & $150 \mathrm{l} / \mathrm{h}$ \\
\hline Steady-state liquid usage & $70 \mathrm{l} / \mathrm{h}$ & $120 \mathrm{l} / \mathrm{h}$ \\
\hline Liquid storage capacity & 38001 & 38001 \\
\hline Liquid storage pressure & $140 \mathrm{kPa}$ & $140 \mathrm{kPa}$ \\
\hline Gas storage capacity & $250 \mathrm{MPa}-\mathrm{m}^{3}$ & $370 \mathrm{MPa} \cdot \mathrm{m}^{3}$ \\
\hline Compressor flow rate & $50 \mathrm{~g} / \mathrm{s}$ & $100 \mathrm{~g} / \mathrm{s}$ \\
\hline Compressor outlet pressure & $1.6 \mathrm{MPa}$ & $1.6 \mathrm{MPa}$ \\
\hline Compressor iniet pressure & $108 \mathrm{kPa}$ & $108 \mathrm{kPa}$ \\
\hline \multicolumn{3}{|l|}{ Nitrogen system } \\
\hline Liquid storage capacity & 40.0001 & 40.0001 \\
\hline Liquid storage pressure & $400 \mathrm{kPa}$ & $400 \mathrm{kPa}$ \\
\hline Steady-state liquid usage & $500 \mathrm{l} / \mathrm{h}$ & $700 \mathrm{l} / \mathrm{h}$ \\
\hline
\end{tabular}




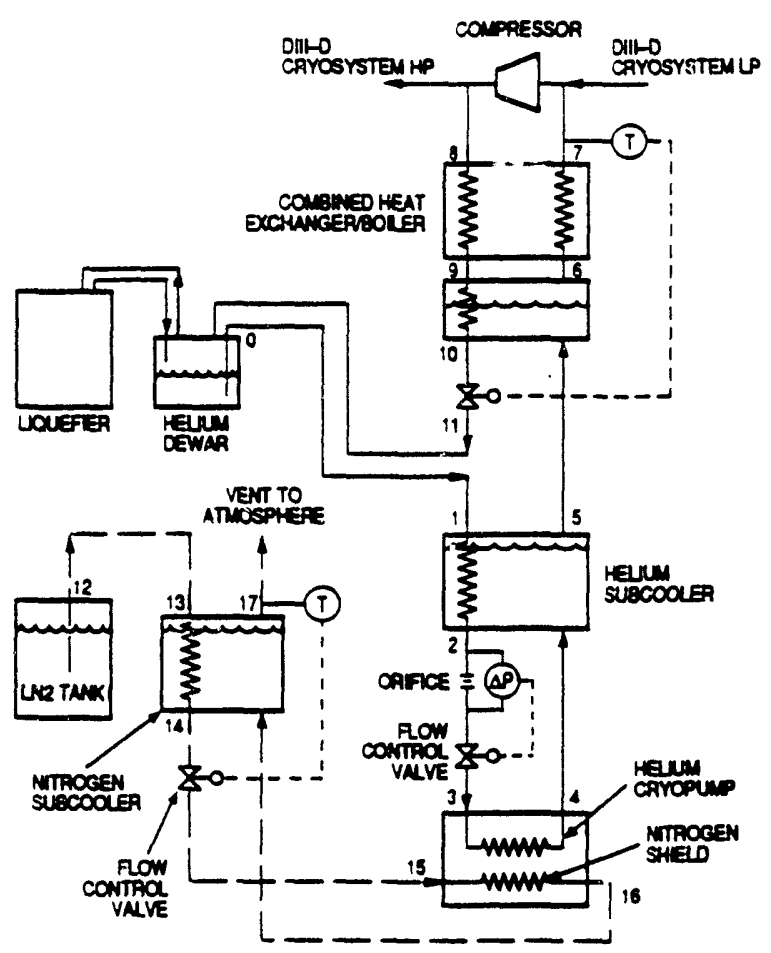

Fig. 3. Simplified AD eryogenic system flow diagram.

the liquefier to provide refrigeration. The heat exchanger is designed to have an effectiveness [7], $\epsilon$, of $98.8 \%$ where $\epsilon$ is defined as

$$
\left.\epsilon=\frac{T_{B}-T_{0}}{T_{B}-T_{6}} \quad \text { (see Fig. } 3\right)
$$

Given this effectiveness, the load imposed on the DIII-D liquefier by the $A D$ cryosystem will be $16 \mathrm{l} / \mathrm{h}$ due to the heat exchanger flow imbalance and $17 \mathrm{~W}$ of refrigeration at $4.6^{\circ} \mathrm{K}$ due to incomplete liquefaction by the Joule Thomson expansion.

Liquid nitrogen will be fed from a pressurized 40,000 I bulk storage dewar. The nitrogen will be subcooled and then throttled into the shield through a temperature controlled valve so that the nitrogen venting to the atmosphere will be fully vaporized.

The helium liquefier, dewar and distribution valve box are located in the DIII-D cryogenics ares $20 \mathrm{~m}$ away and $3 \mathrm{~m}$ above the cryopump (see Fig. 4). A vacuum insulated cryostat containing the heat exchanger, subcoolers, flow control valves, and the Joule-Thomson valve will be located adjacent to the cryopump feed port on DIII-D. The cryostat will be at the same ele:ration as the cryopump to avoid two-phase flow instability associated with elevation changes. The beat exchanger was designed and constructed by Cryogenic Consultants Incorporated. It consists of a phase separation boiler and a high efficiency counter-flow heat exchanger constructed with wound finned copper iuving. The subcoolers will consist of $7.5 \mathrm{~m}$ of coiled copper tubing housed in a stainiess steel shell and are designed to cool the incoming liquid to within $0.1^{\circ} \mathrm{K}$ of the cryopanel outlet liquid temperature. All helium cooled components within the cryostat will be superinsulated and protected by a liquid nitrogen cooled radiation shield.

The present distribution valve box contains 16 manually operated valves which are used exclusively for the neutral beamlines. The valve box will be replaced with a new box containing 20 zutomatically operated electro-pneumatic cryogenic valves to serve the AD cryopump, neutral beamlines, ECH magnet fill, and pellet injector fill. Heat leakage will be minimized by vacuum insulation, superinsulation, $80^{\circ} \mathrm{K}$ thermal intercepts on the valve bodies, and a liquid nitrogen cooled radiation shield.

Liquid belium will flow between the dewar and the distribution box through a pair of short vacuum jacketed transfer lines. Liquid helium supply, two-phase helium return and liquid nitrogen supply will be transferred between the distribution box and the cryostat via a triaxial flexible metal transfer line manufactured by Kabelmetal [8]. The Kabelmetal transfer line has the advantages of minimum heat lealage and easy installation due to its flexibility and bayonet type end connections.

\section{Instrumentation and Control}

The objective of the instrumentation and control design (Fig. 5) for the AD cryopump system is to provide the means to automatically operate the system in concert with related and interconnected systems. Data acquisition for problem diagnosis and performance evaluation in addition to provision for manual operation are aloo important.

Automatic operation will involve controlling the valves to accomplish the following taaks:

1. Precooling of the transfer lines.

2. Cooldown of the cryopump.

3. Liquid helium and nitrogen flow control.

4. Heat exchanger secondary flow control.

5. Regeneration of the helium panel between DIII-D shots.

6. Warm-up of the AD cryosystem.

The dependence of the AD cryosystem upon the DIII-D cryogeaics system [9] will require interlocking with the cryogenic control programmable logic controller (cryo-PLC). DIII-D primary vacuum conditions will govern the operation of the cryopump indicating the need for coordination with the DIII-D vessel conditioning PLC. This system controls vacuum pumping, baking, and discharge cleaning. An interface to the machine control computer will allow the martine operators supervisory information on pump status and ability to initiate or terminate DIII-D synchronous operation. Synchronous operation will also require signais from the machine master timing system. An orerator interface at the engineering level will be necessary to obtain detailed operating information, data logging, analysis, and maintenance.

Table 2

$A D$ Cryosystem Thermodynamic States"

\begin{tabular}{crrrrrrr}
\hline Location & $\begin{array}{c}\mathrm{T} \\
\left({ }^{\circ} \mathrm{K}\right)\end{array}$ & $\begin{array}{c}\mathrm{P} \\
(\mathrm{kPa})\end{array}$ & $\begin{array}{c}\mathrm{hf} \\
(\mathrm{J} / \mathrm{gm})\end{array}$ & $\begin{array}{c}\mathrm{hg} \\
(\mathrm{J} / \mathrm{gm})\end{array}$ & $\begin{array}{c}\mathrm{ha} \\
(\mathrm{J} / \mathrm{gm})\end{array}$ & $\begin{array}{c}\mathrm{m} \\
(\mathrm{gm} / \mathrm{s})\end{array}$ & $x$ \\
\hline 0 & 4.6 & 143 & 12.3 & 30.3 & 12.3 & 5.0 & 0.00 \\
1 & 4.6 & 145 & 12.4 & 30.3 & 13.2 & 5.0 & 0.06 \\
2 & 4.4 & 144 & 11.1 & - & 11.1 & 5.0 & 0.00 \\
3 & 4.3 & 116 & 10.8 & 30.7 & 11.1 & 5.0 & 0.02 \\
4 & 4.3 & 114 & 10.7 & 30.7 & 13.1 & 5.0 & 0.12 \\
5 & 4.3 & 113 & 10.6 & 30.7 & 15.2 & 5.0 & 0.23 \\
6 & 4.3 & 112 & 10.6 & 30.8 & 30.8 & 5.0 & 1.00 \\
7 & 270.0 & 110 & - & 1420.0 & 1420.0 & 5.0 & 1.00 \\
8 & 300.0 & 1200 & - & 1580.0 & 1580.0 & 4.5 & 1.00 \\
9 & 7.9 & 1000 & - & 33.2 & 33.2 & 4.5 & 1.00 \\
10 & 4.8 & 1000 & - & 15.9 & 15.9 & 4.5 & 1.00 \\
11 & 4.6 & 145 & 12.4 & 30.3 & 15.9 & 4.5 & 0.20 \\
12 & 91.6 & 412 & -91.3 & - & -91.3 & 10.0 & 0.00 \\
13 & 91.5 & 410 & -91.4 & 85.7 & -87.5 & 10.0 & 0.02 \\
14 & 78.0 & 409 & -119.9 & - & -119.9 & 10.0 & 0.00 \\
15 & 78.0 & 117 & -119.9 & - & -119.9 & 10.0 & 0.00 \\
16 & 78.5 & 115 & -119.1 & 78.0 & -109.9 & 10.0 & 0.05 \\
17 & 77.9 & 108 & -120.3 & 77.6 & -77.5 & 10.0 & 0.22 \\
\hline
\end{tabular}

- Refer to Fig. 3. 


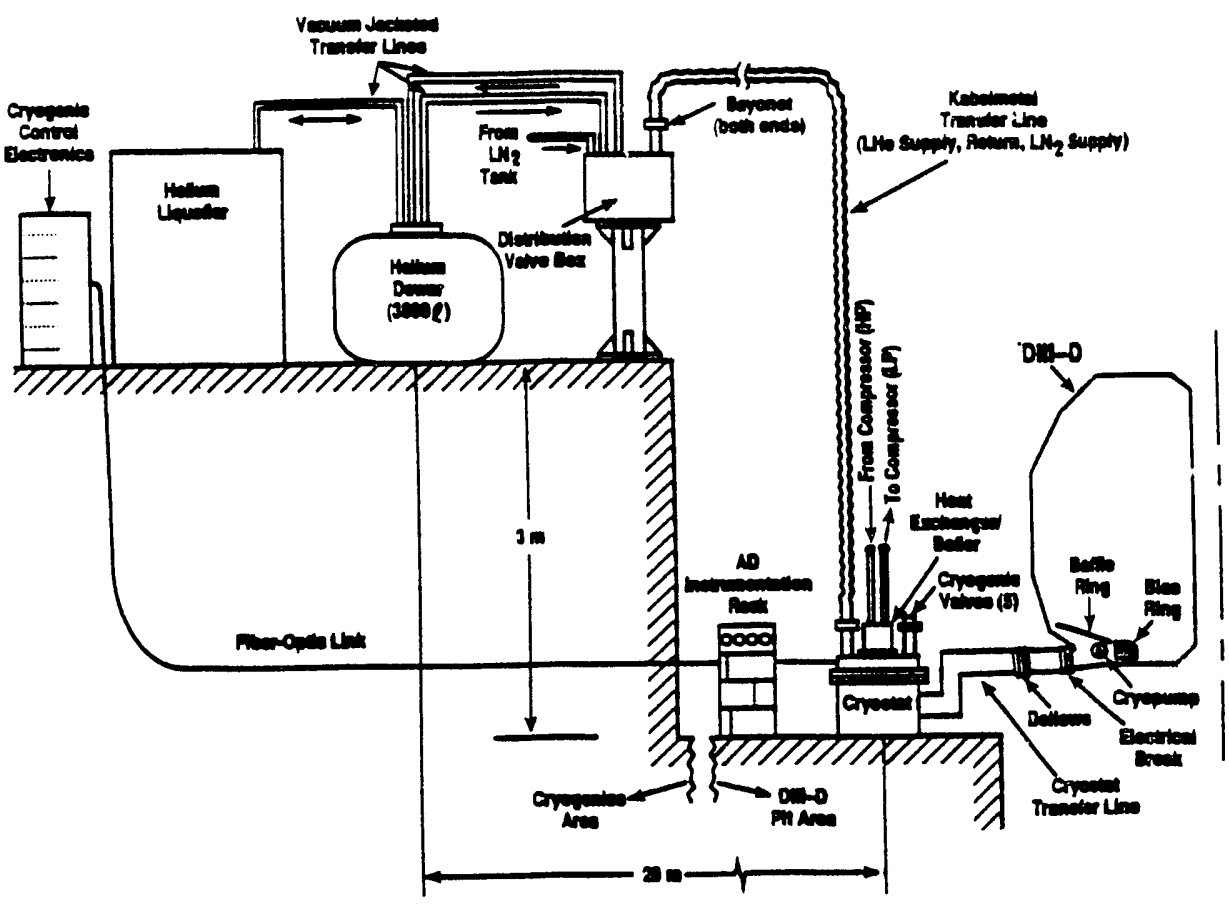

Fig. 4. $A D$ eryosystem equipment arrangement. Elevation view.

Since much of the AD cryosystem will be located in the restricted machine area, all cryostat valves will be remotely controlled. Extensive use of electronic and electromechanical sensors will characterize the control system implementation. A limited number of mechanical gauges and electronic rendouts will be used at the cryostat site due to lack of local control capability. Control system inputs will come from sixteen temperature sensors, ten pressure sensors, three flow control valve positions and two level indicators. Outputs will include five proportional valves and seven isolation valves. Temperatures will be measured using a combination of helium vapor presoure bulbs equipped with electrical pressure transducers, silicon diodes, and thermocouples. Spare sensors will be mounted and wired at all silicon diode and thermocouple measurement locations inside of the vacuum space to provide redundancy in case of sensor failure.

The close association between the AD cryosystem and existing cryogenics systems makes it desirable to control the cryopump from the cryo-PLC. Thus, the cryo-PLC will be upgraded using a fiber-optically isolated I/O system and ability to accommodate cryostat sensors and valves. The cryogenics control system employs a personal computer based color graphics operator interface sufficient for use as the engineering level operating console for $A D$ cryosystem. The cryo-PLC will fully support the $A D$ cryosystem operation and provide a bigh speed data link to the vessel conditioning system. The ressel conditioning PLC has access to the machine control computer and to the master timing signals.

\section{Acknowiedgment}

This work was sponsored by the U.S. Department of Energy under Contract No. DE-AC03-89ER51114.

\section{References}

1. Mahdavi, M.A., "The DIII-D Collaborative Advanced Divertor Program," General Atomics Report GA-A 19547 (1989).

2. Menon, M.M., et al., "Particle Exhaust Scheme Using an In-Vessel Cryocondensation Pump," General Atomics Report to be published.

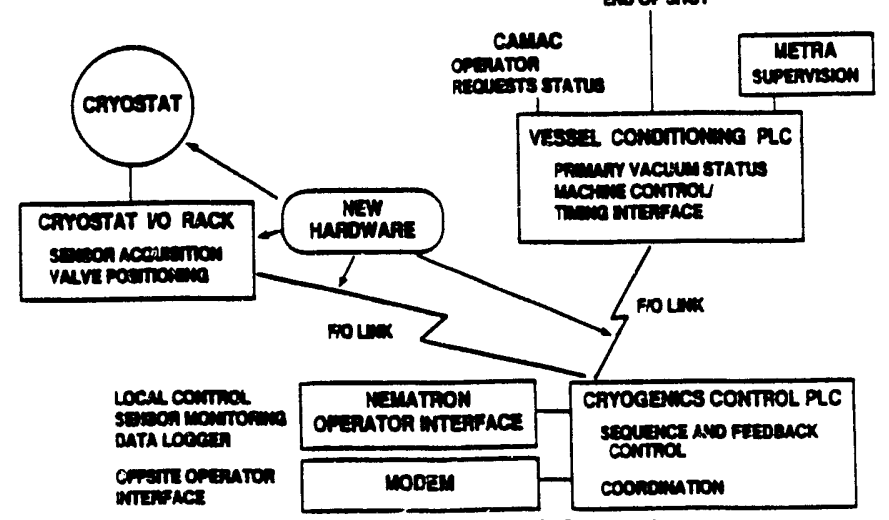

Fig. 5. ADP eryostat $1 \& C$ overview.

3. Smith, J.P., etal., "The Design and Fabrication of a Toroidally Continuous Cryocondensation Pump for the DIII-D Advanced Divertor," to be presented at the 14th Fus. Eng. Conf., San Diego, California, September 30 through October 3, 1991.

4. Langhorn, A.R., etal., "Performance of Doublet III Neutral Beam Injector Cryopumping System," J. Vac. Sci. Technol. A 2(2) (April-June 1984) 1193.

5. Langhorn, A.R., "The Doublet III Neutral Beam Injector Cryosystem," Advances in Cryogenic Engineering, Vol. 29. Plenum, New York (1983) 393.

6. Baxi, C.B., etal., "Verification Test for Helium Panel of Cryopurap for DIII-D Advanced Divertor," to be presented at the 14th Fus. Eng. Conf., San Diego, California. September 30 through October 3, 1991.

7. Barron, R.F., "Cryogenic Systems," 2nd Ed.. Oxford University Press, New York (1985) 123.

8. Blessing, H., et al., "High Pr formance Flexible Cryogenic Helium Transfer Lines," Advances in Cryogenic Engineering, Vol. 27, Plenum, New York (1981) 761.

9. Campbell, G.L., and J.J. Gilgallon. "DIII-D Cryogenic Control System Upgrade," Proc. IEEE Thirteenth Symp. on Fusion Eng., Knoxville, 1989, 1 (1990) 167. 

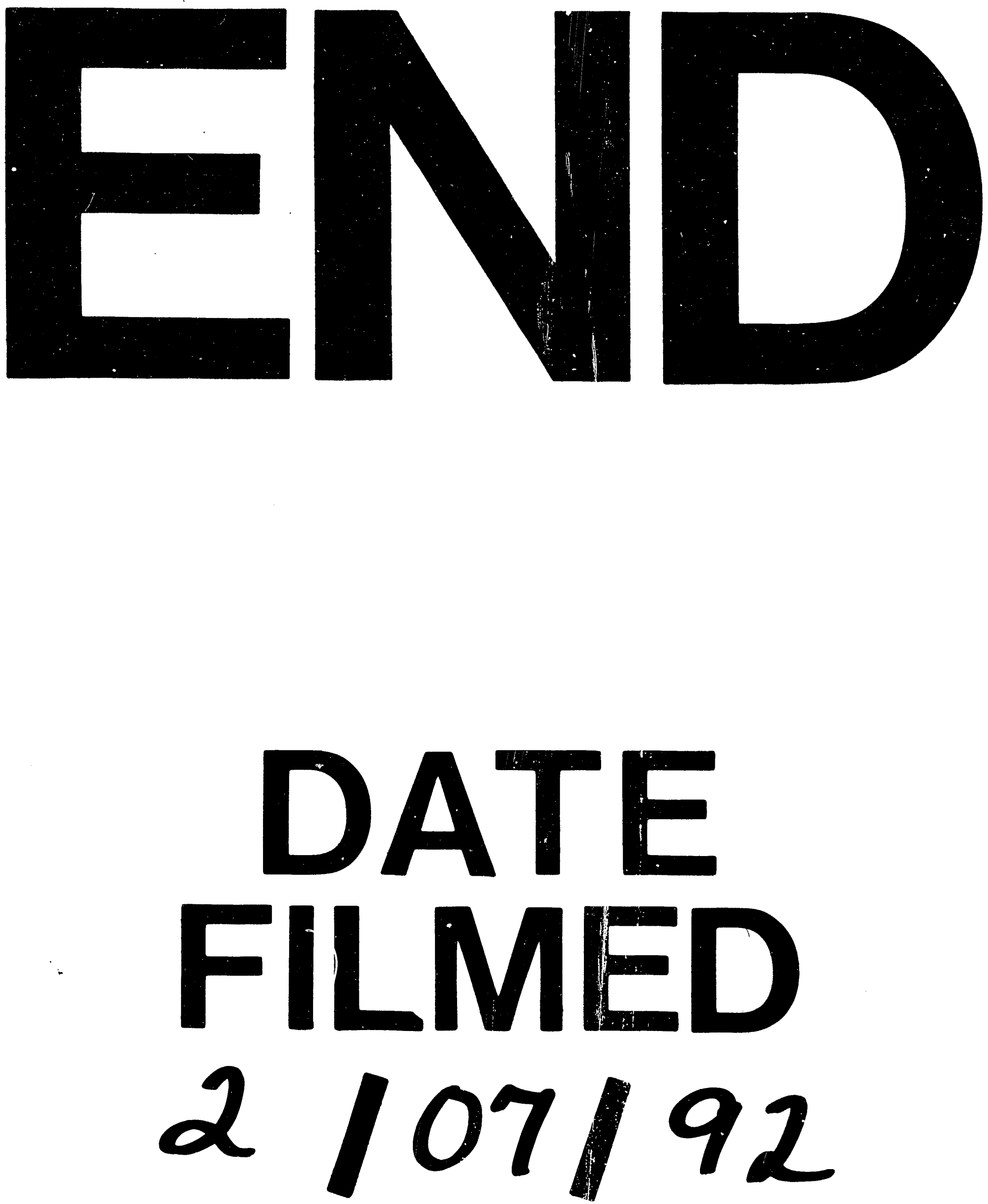

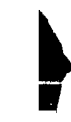


